\title{
PELA FÉ, CONTRA O HEREGE: ODILON ALVES PEDROSA E OS DEBATES ANTIESCOLA PROTESTANTE NA GAZETA DE NAZARÉ (1931-1935)
}

\author{
FOR THE FAITH, AGAINST THE HEREGE: ODILON ALVES \\ PEDROSA AND THE DISCUSSIONS ANTI PROTESTANT SCHOOLS \\ IN GAZETA DE NAZARÉ (1931-1935)
}
POR LA FÉ, CONTRA EL HEREGE: ODILON ALVES PEDROSA $Y$ LOS DEBATES ANTIESCOLA PROTESTANTE EN LA GAZETA DE NAZARÉ (1931-1935)

RAmSÉs Nunes E SiLVA ${ }^{1}$

Resumo A construção de espaços de debate, postulados pela intelectualidade católica, formada nos bancos das universidades romanas, em plena efervescência do ultramontanismo, e das rusgas contrárias à secularização das sociedades, tomaram rumos distintos, conforme se exibiam conjunturas favoráveis ao debate sobre modelos escolares. A liberdade de culto no Brasil, disposta pela Constituição de 1891, não se encerraria como tema de debates a se apresentarem ainda contundentes, por volta dos anos 1930. Nosso artigo, dedica-se a refletir a respeito das querelas que insurgiam na cidade de Nazaré da Mata (PE), exatamente naquela conjuntura, onde a função de diretor do jornal Gazeta de Nazareth, dada ao padre Odilon Alves, potencializaria a efervescência de certo protagonismo militante. Especialmente, sendo aquele intelectual artífice da disputa de modelos culturais e escolares, localmente. Debate oriundo daquela espécie de guerra de textos, encetada na expansão de novas sociabilidades, particularmente advindas da presença na cidade do protestantismo. De onde se apresentou, junto ao principal periódico diocesano local, um profícuo espaço de disputas discursivas. Parte significativa delas, cuja temática era a instrução e as práticas culturais não católicas, era objeto de enfrentamentos diários.

Palavras-chave: Instrução confessional; Intelectuais católicos; Protestantismo.

Universidade Estadual da Paraíba, Campus V, João Pessoa, PB. 
Abstract The construction of spaces for debate, postulated by the Catholic intelligentsia, formed in the banks of the Roman universities, in the midst of the ultramontanism, and the raids against the secularization of societies, took different paths, as there were favorable conjunctures for the debate on school models. The freedom of worship in Brazil, established by the constitution of 1891, would not close as a subject of debates to present themselves still forceful, around the 1930s. Our article is dedicated to reflect on the quarrels that insurrected in the city of Nazare da Mata (PE), precisely at that juncture, where the function of director of the newspaper Gazeta de Nazareth, given to Cleric Odilon Alves would enhance the effervescence of some militant protagonism. Especially, being that intellectual architect of the dispute of cultural and school models, locally. Debate from that kind of war of texts, initiated in the expansion of new sociabilities, particularly coming from the presence in the city of Protestantism. Where he presented himself, together with the main local diocesan newspaper, a proficient space of discursive disputes. A significant part of them, whose subject matter was non-Catholic cultural instruction and practices, were the subject of daily confrontations.

Key-words: Confessional Instruction; Catholic Intellectuals; Protestantism.

Resumen La construcción de espacios de debate, postulados por la intelectualidad católica, formada en los bancos de las universidades romanas, en plena efervescencia del ultramontanismo, y de las rusas contrarias a la secularización de las sociedades, tomaron rumbos distintos, conforme se presentaban coyunturas favorables al debate sobre modelos escolares. La libertad de culto en Brasil, dispuesta por la Constitución de 1891, no se encerraría como tema de debates a presentarse todavía contundentes, hacia los años 1930. Nuestro artículo se dedica a reflexionar sobre las querellas que insurgían en la ciudad de Nazaret de la Mata (PE), precisamente en aquella coyuntura, donde la función de director del diario Gazeta de Nazareth, dada al padre Odilon Alves, potenciaría la efervescencia de cierto protagonismo militante. Especialmente, siendo aquel intelectual artífice de la disputa de modelos culturales y escolares, localmente. Debate oriundo de aquella especie de guerra de textos, iniciada en la expansión de nuevas sociabilidades, Particularmente venidas de la presencia en la ciudad del protestantismo. Donde se presentó, junto al principal periódico diocesano local, un provechoso espacio de disputas discursivas. Una parte significativa de ellas, cuya temática era la instrucción y las prácticas culturales no católicas, era objeto de enfrentamientos diarios.

Palabras clave: Instrucción Confesional; Intelectuales católicos; Protestantismo.

\section{INTRODUÇão}

A dimensão da formação constituída nos seminários espalhados pelo Brasil, que produziu toda uma geração de intelectuais, desde o século XIX, apresentava-se urgente em meados dos anos 1920, haja vista certa arregimentação das lideranças clericais, para que 
fossem produzidos textos combativos, no formato de Cartas Pastorais, documentos curiais nos quais a exortação contra as confissões não católicas era contundente, especialmente no tocante a críticas relativas à instrução de matriz protestante, ou de qualquer credo que não o católico, de onde a transmissão de capitais simbólicos, entre os que nos aponta Bourdieu (1996), eram icônicos.

Muitos, devemos lembrar, convergiram com o clima de embate de universos, particularmente entre modelos socioculturais do secularismo e da confessionalidade (MARRAMAO, 1994), o último imantado com leituras críticas, alinhadas a lideranças como as do bispo Dom Sebastião Leme e de instituições na linha do Centro Dom Vital, no Rio de Janeiro, líder intelectual e espaço de publicação e fundamentação católico, respectivamente.

A Carta coletiva editada em 1916, por exemplo, é considerada uma publicação-marco no ativismo romanizado do período, particularmente na profunda reflexão que aquele documento realiza na seara das metas de expansão, afirmação e combatividade que o catolicismo ensejava, conforme destacam Miceli (1988) e Vilaça, (2006). Fenômeno que retomava uma importância basilar na dinâmica política da igreja, destituída dos meandros do poder desde a proclamação da República e do fim do padroado, com a Constituição de 1891, documento que tornava a escola laica, pelo menos no âmbito dos dispositivos da legislação instrucional (SILVA, 2006).

De igual modo, seminários como os de Olinda, em Pernambuco, tornaram-se verdadeiros celeiros de formação, bem como, de instrumentalização dos desígnios da Sé romana, onde se esperava que jovens, oriundos das mais diversas cidades daquele Estado e da região Nordeste se preparassem para uma espécie de guerra doutrinária. Aquela que parece ter sido instalada na sequência de uma espécie de recatolicização da sociedade brasileira, da qual nos fala Azzi (1998), e de um processo de estadualização das dioceses, como destaca Miceli (1988).

Sintomaticamente, a ida de uma série de jovens para universidades de Teologia e Direito Canônico, como a Pontifícia Universidade Gregoriana em Roma, e para outras instituições europeias, reforçou o quadro de intelectuais engajados numa militância que permaneceu reforçada, nos anos seguintes, fosse pelo caráter do missionarismo vigente ou do espírito de corpo formado entre os estudantes internados nas escolas, seminários e universidades europeias. Da mesma forma na América do Sul, como identificam Cambi (2002) e Kulesza (2010).

Nosso biografado, menino de engenho da Zona da Mata pernambucana, instruído nas primeiras letras junto àquele universo de protagonismos, pelos idos da década de 1910, pode ser entendido como um partícipe daqueles signos, muitos dos quais introjetados em seu alistamento sob o escrutínio da patronage, ${ }^{2}$ manifestação apresentada a jovens moços, oriundos do interior, e que se embrenhavam nas mediações da Sé romana para, quando suficientemente preparados, ingressarem em seus quadros.

2 Fenômeno de arregimentação - de foro particular ou institucional - de jovens de ambos os sexos para os quadros da igreja, que pudessem ser patrocinados financeiramente em seus estudos. 
Já na década de 1920 os eventos intensificaram-se, a influírem nas trajetórias clericais/ estudantis. Odilon Alves Pedrosa, estudante seminarista, formado naquela instituição, acabou alçado à condição de protagonista de tessituras socioculturais, na qual se engajou de forma veemente, enquanto veterano, nos espaços de leitura, estudo e militância romanos e como padre ordenado, a publicar seções de correspondência para o Brasil.

\section{Militante e Padre ordenado: rumo a Nazaré da Mata}

Em 1927, após quatro anos de formação, o recém-doutor em Direito Canônico retornava a Pernambuco, oriundo de um dos maiores centros de formação católicos europeus. Pedrosa, agora padre, havia sido ordenado pela Pontifícia Universidade Gregoriana, instituição de instrução superior, responsável pela ordenação de uma importante gama de sacerdotes brasileiros, entre o final do século XIX e o início do século XX.

O padre Odilon naquela conjuntura mergulhou na esfera das práticas políticas de sua antiga diocese, Nazaré da Mata. O combate almejado nos tempos de estudante adquiriu um sentido ainda mais engajado quando seus objetivos, traçados desde o Seminário de Olinda, passando pela Pontifícia Universidade Gregoriana, por seus tutores intelectuais em Roma, ${ }^{3}$ e por lideranças como Ricardo Ramos de Castro Villela, bispo de Nazaré, se manifestaram na militância. Como declarou Pedrosa (1927) em seu Diário do Seminário: Não era para ser encerrado tão só, numa paróquia de Recife que, muito rápido, me vi na estrada de ferro rumo a Nazaré da Mata.

Todas as teorizações nas quais tinha mergulhado, à luz do que debatiam os eruditos italianos, franceses e portugueses, foram colocadas à prova. Também é verificável que o jovem padre acabasse por ansiar, já no desembarque, pelo início de suas atividades naquilo que tinha longamente estudado, e agora "exerceria": o combate discursivo e doutrinário, embora, naquele final de década conturbado pelos movimentos políticos e sociais pelos quais o Brasil passava, entre eles, segundo Skidmore (2010), o tenentismo, estivessem a ser reconduzidas algumas de suas bases políticas oligárquicas.

Naquele momento suas atribuições, entre elas a função de pároco, acabaram por ser minimizadas. Outras ações naquele palco convulsionado que era Pernambuco mostraramse imprescindíveis: 1) as de teólogo e doutor em Direito Canônico, basilar para a diocese que o abraçava; 2) jornalista diletante e militante político, com já larga experiência na editoração de periódicos; e 3) educador católico engajado, atividade que funcionaria como lastro de sua produção e afirmação teórica, num primeiro momento, ali mesmo em Nazaré da Mata, junto a novos seminaristas e também alunos (as) internos (as), nos colégios confessionais locais.

3 Odilon Pedrosa foi correspondente da revista Maria, onde escreveu a coluna De Roma, responsável por informar os fiéis brasileiros dos encaminhamentos da Sé romana. Também exerceu função de secretário e integrante da Academia Beato Ignacio Azevedo, círculo intelectual de seminaristas latino-americanos, localizado no Pontifício Colégio Pio Latino-Americano. 
Tal retorno foi pontuado imediatamente com a oferta de funções importantes naquela jurisdição eclesiástica. Não era uma exceção ou privilégio, mas uma disposição curial na qual aquele recém-chegado era peça-chave, no front que se abria. Nazaré agora é meu lugar de combate. Há muito a ser feito (PEDROSA, 1927, p. 9). Até mesmo porque aquelas funções, orquestradas pessoalmente pelo então bispo Dom Ricardo Vilela, como estratégia de reforço à sua liderança, representavam uma forma de cimentar a empatia, entre os paroquianos locais, particularmente, no ato de fixar um padre oriundo dos mesmos espaços rurais.

Afinal, Odilon Pedrosa, como tantos outros padres, era conterrâneo de muitos chefes políticos locais, muitos, inclusive, parentes. Circulava facilmente entre os naturais da terra, uma particularidade chave nas sociabilidades que se queria fossem encaminhadas o mais breve possível. Também dispositivo comumente utilizado pela igreja, nos rincões do interior de Pernambuco, assim como o soerguimento de um cada vez mais efetivo aparato patrimonial. Haja vista espaços físicos construídos ou alocados em Nazaré da Mata, desde a criação da diocese, em 1918. Foi marcante a afirmação do Seminário Menor e o funcionamento do Ginásio Leão XIII. Aquela cidade, sede diocesana e administrativa para muitas outras povoações era, em meados dos anos 1920, sede do catolicismo oficial da Zona da Mata. Toda a riqueza canavieira, diga-se, ainda irrompia pelas veredas dos engenhos e se transladava às inter-relações citadinas.

É de se observar, entre as missões eclesiásticas, particularmente dadas a um recémordenado padre, o combate a outras profissões religiosas e ideários políticos e filosóficos, entre eles, o protestantismo, espiritismo, laicismo e a maçonaria, princípios e confissões que se apresentavam em franca expansão na cidade de Nazaré da Mata, nos últimos anos, parte deles potencializada numa esfera minimamente urbanizada, que recebia uma gama cada vez maior de partícipes civis secularizados.

É impactante a condição de Nazaré da Mata, por volta da transição entre as décadas de 1920 e 1930. A cidade possuía, segundo o Almanak Administrativo, Mercantil e Industrial do Rio de Janeiro, em sua listagem dos municípios brasileiros detentores de um perfil de progresso, largo e próspero comércio, assim como uma singularidade social, cultural, econômica e política, muitíssimo particular na Zona da Mata pernambucana.

Tanto que denotava uma atitude estratégica por parte da diocese em relação às escolas, associações, órgãos de imprensa, tipografias, fábricas, farmácias, teatros e cinemas, aspecto que reforçou a imagem da cidade como seara de disputas simbólicas, dentro de variados capitais socioculturais. Entre eles, os que incidiriam no mesmo fenômeno que se abateu sobre Recife e Olinda: a modernização imbricada no surgimento de setores sociais intermediários e protagonismos distintos do universo católico, condição subjacente à instalação da nova ordem, distante da que era construída pelo universo disciplinar proposto pela Santa Sé.

O Almanak ainda destaca nesse item a existência, por exemplo, da Igreja Batista na cidade com duas congregações: em Carpina e no Engenho Gregório, igreja essa detentora de três associações: Sociedade Juvenil, Sociedade de Moços e Sociedade de Senhoras. $\mathrm{Na}$ mesma forma, a liderança e atuação de agentes intelectuais do espiritismo. Todo um arcabouço de disputas políticas e teológicas se faziam presente na cidade, aspecto pontual 
das sociabilidades locais, que já estavam a ser combatidas a partir da fundação de espaços escolares, como o Internato Santa Cristina, colégio fundado em 1924 pelas Damas da Instrução Cristã, como parte da arregimentação católica de estudantes do sexo feminino.

Há indícios de que Odilon Pedrosa exerceu, segundo Pessoa (2003, p. 123), a função de professor e representante docente de 1931-1935, junto ao curso comercial naquele internato feminino. Não foi, evidentemente, a única função na qual Odilon Pedrosa exerceu papel de protagonista, na batalha intelectual que se avizinhava da cidade de Nazaré da Mata.

É importante destacar que o bispo Dom Vilella o encaminhou, em 1928, bem antes do envolvimento do padre Odilon no Santa Cristina, para uma dupla função: 1) artífice e novo administrador na transição da liderança do Seminário Menor e do Ginásio Leão XIII (anteriormente levados a cabo pelo padre Álvaro Negromonte); e 2) direção da Gazeta de Nazareth, o principal periódico católico diocesano.

\section{A Gazeta de Nazareth e as Querelas antiescola Protestante}

A cidade de Nazaré da Mata já possuía uma exponencial circulação de periódicos, desde o Oitocentos com características as mais diversas, como bem destaca Nascimento (1966, p. 180), na clássica obra História da imprensa em Pernambuco. Nos anos 1920, a Gazeta de Nazareth, de escopo inicialmente secular, pertencente à iniciativa privada da cidade, inclusive com participação das mais diversas esferas intelectuais, se destacaria pelas polêmicas apresentadas entre seus colaboradores, como as que envolveram, em 1926, João M. Vieira de Melo e o padre Álvaro Negromonte, os dois, segundo Nascimento (1966, p. 180), às voltas com o tema do ensino religioso nas escolas.

A Gazeta, tendo disponibilizado um perfil editorial de liberdade de credos e temáticas, em sua primeira fase, acabou por permitir convergências e disputas internas de escopo acirrado, sobretudo, heterogêneas. Aspecto que se tornou contraditório quando não contraproducente, na esfera das relações discursivas que se apresentavam, pelo menos, até aquele fatídico ano de 1926, no qual se digladiavam dois representantes daquilo que será a tônica dos futuros debates, postos no jornal.

Laicos versus confessionais. Todo um ambiente que contrapunha discursos adversários se apresentou diariamente aos leitores num quadro prenhe de situações limites. Bastava um rastilho para que se exibissem as armas. Iniciava, assim, uma fase eminentemente combativa, em que estiveram como redatores-chefes o monsenhor João da Mata Amaral e, a partir do número 634 da Gazeta de Nazareth - de 12 de janeiro de 1929 - Odilon Pedrosa, embora este já fosse responsável por uma série de artigos, conforme registros contidos nos Recortes dos artigos que publiquei na Gazeta de Nazareth, parte deles sob o pseudônimo de João de Nazareth. ${ }^{4}$ Estaria, assim, pontuada uma espécie de missão como docente e

4 Identificamos em nossa pesquisa pós-doutoral (Universidade do Minho - 2018) referência direta a tal prática no Diário do Seminário de Odilon Pedrosa. Manuscrito escrito entre 1924 e 1927. Narrativa na qual o dispositivo de acobertar o pertencimento aos quadros intelectuais do clero, com uso de pseudônimo, era sobretudo instrumento eficiente, segundo o clérigo. Notadamente no trato com as confissões religiosas rivais, haja vista que dava maior autonomia no debate sobre temáticas polêmicas. Especialmente em Pernambuco, nos anos 1920. 
jornalista católico, função que Odilon Pedrosa acreditou enfeixar e que o acompanhou por uma parte significativa de sua vida sacerdotal.

Ao iniciar na esfera diocesana, exatamente no ponto em que a Gazeta já adquirira uma homogeneidade discursiva, Odilon Pedrosa tudo faria para dar continuidade e celeridade ao processo de embate já bastante adiantado, nos últimos anos, e que ele potencializou. As leituras aprofundadas no curso superior em Roma o fariam considerar naquela transição entre as décadas de 1920 e 1930, entre outras temáticas, o ensino como atributo combativo, no mesmo patamar do jornalismo engajado, ambos centrados na capacidade de formar cristãos que acreditava se distanciavam da tutela docente ou, pior, aceitavam o credo da secularidade e do protestantismo. Manifestação potencializada numa esfera considerada ameaçadora: a dos princípios sociais, culturais e educacionais que não estivessem alinhados com os postulados pelo catolicismo. Seara na qual a Gazeta de Nazareth protagonizaria polêmicas acirradas, por muitos anos ainda.

Ainda no edital em que assumiu a liderança do principal periódico católico de Nazaré, escreveu Odilon Pedrosa a que viria, imbuído de toda carga voluntarista. Era o dia 12 de janeiro de 1929:

\begin{abstract}
Nova Fase (...). Com a transferência dos direitos de propriedade sobre a Gazeta de Nazareth do monsenhor João da Mata para esta Diocese, nossa folha ingressa numa nova fase de trabalho não menos digna nem menos operosa. (...) Órgão livre, ligação de partidos nem de conveniências pequeninas, seremos como sempre, sem alteração de programa, os batalhadores decididos pela conquista de novos e eficientes progressos para Nazaré, os defensores da causa católica na Diocese, os guerrilheiros audazes contra os difamadores, os corruptos, os caluniadores, os mentirosos. Na batida desta rota não mediremos sacrifícios. Assim o exijam o bem da Igreja e o de nossa terra. Não nos faltam penas amestradas para o aceso dos combates. A mudança de propriedade não implica na Gazeta de Nazareth a deserção do velho elemento literário, que vem colocando nossa filha, modéstia à parte em elevado plano na imprensa pernambucana (GAZETA DE NAZARETH, 1929, p. 1).
\end{abstract}

Naqueles anos, o padre-educador Odilon Pedrosa teve como meta executar, minimamente, dentro das condições ofertadas pela diocese de Nazaré da Mata, o que estava previsto nas Encíclicas Papais para a instrução católica: ataque à mundaneidade e oposição às crenças não católicas. Momento chave na trajetória de Odilon Pedrosa pela sagacidade, criatividade e verdadeira campanha discursiva que o intelectual passou a protagonizar no periódico, nos anos seguintes, ininterruptamente. Suas funções na diretoria do Seminário Menor e do Ginásio Leão XIII foram mantidas, alternadamente, com as atividades de diretor e editor de a Gazeta.

É impactante, mas evidentemente legítimo, para seus padrões enquanto intelectual de seu tempo, que suas leituras fossem convergentes com a linha de pensamento de rompimento, bem como, endurecimento no tocante à organização da sociedade civil. Nesse espaço, colecionou artigos a partir de janeiro de 1928, particularmente engajados num profundo 
antagonismo cultural, ideológico e militante, discursivamente contrário, por exemplo, ao protestantismo.

Anos depois, em outra obra memorialista, Do meu Bisaco, Odilon Pedrosa destacou aqueles dias em plenos anos 1920, como sendo tempos de combate acirrado, onde não havia qualquer espaço para concórdia, ainda mais entre modelos culturais antagônicos:

O tempo era de brigas. Nos jornais todo mundo polemizava. Ninguém pisava os calcanhares do outro sem que este gritasse. Os desvios no meio político provocavam reparos. A imprensa era um posto avançado de vigilância. Havia participação mais viva e profunda dos homens de Imprensa no tumulto da cousa pública. Se assim se portavam na área profana, no plano religioso a tendência era mais acentuada ainda. Havia no ar um gostinho sádico de morder a Igreja, criticar os seus ministros, falar mal do sagrado do transcendente (PEDROSA, 1986, p. 23).

O protagonismo de enfrentamento, centrado na doutrinação que convergia pela via educacional, política e jornalística era plataforma assumida dos intelectuais católicos nos anos 1920. Odilon Pedrosa se apresentava naquela tessitura, nem sempre da conciliação. Ora, todo aquele sentido missionário, fomentado por anos seguidos como estudante, ou aquele sentimento de pertença à militância, na qual suas características de liderança e impetuosidade literária se somaram às ordens que partiam de Roma, estaria em xeque.

Em Pernambuco, jornais como A Tribuna faziam o mesmo papel, que era de publicitação das temáticas de enfrentamento discursivo, caras ao posicionamento católico. Com ele, por tabela, as polêmicas nos mais variados campos.

Odilon Pedrosa, já como padre ordenado, era à época assíduo leitor de Carlos de Laet, Leonel Franca e Alceu Amoroso Lima, articulistas devidamente lidos, minuciosamente, como atesta a posse de cópias das obras daqueles intelectuais, e a assinatura - já desde 1928 - de A Ordem.

Nas mãos dele, aliás, $A$ Gazeta, seguindo a orientação episcopal, se tornaria marca ainda mais efetiva de uma época de profundo antagonismo, de onde uma das principais funções dos órgãos de fomento católico na cidade era o embate:

Ora, eu tinha nas mãos instrumento de combate. A Gazeta de Nazaré era semanário do interior, pequeno de dimensão, mas fazia questão de estar presente, sobretudo no espaço de interesse maior, questões em que estivessem envolvidos interesses da Igreja, da religião (...). Pois bem, seria negar a própria natureza do órgão católico, vivo e atuante na medida de seu poder limitado de ação, se a Gazeta não apresentasse em circunstâncias específicas para a defesa da verdade cristã e bem do povo de Deus. Ao longo da caminhada topamos com muitos contraditores. Agressivos, com ares de quem fosse dono da verdade. E sempre fomos ao encontro deles (PEDROSA, 1988, p. 23-24).

Naquela conjuntura, o padre Odilon Pedrosa definiu como principais contraditores justamente aqueles setores identificados como especialmente contrários às antigas forças 
políticas. Setores que se espalhavam pela cidade, oriundos das chamadas ordens societárias medianas/urbanas, entre eles, médicos, professores, comerciantes e, evidentemente, líderes religiosos não católicos. Uma parte, inclusive, descompromissada com os rituais de submissão aos interesses da igreja, muitos inimigos declarados e oposição direta a jovens padres como Odilon Pedrosa, recém-egresso da Sé romana.

Intelectuais e professores, a exemplo dos advogados Joaquim Pimenta e Metódio Maranhão, além de líderes opositores, articulistas de periódicos rivais de a Gazeta, assim como pastores, como Júlio Leitão de Melo. O último, alvo de sucessivos artigos elaborados para dar vazão aos expurgos impressos que se tornaram práticas comuns, a dependerem dos temas em Nazaré da Mata. No caderno Recortes dos artigos que publiquei na Gazeta de Nazareth, o padre Odilon Pedrosa destacaria, posteriormente, de forma sarcástica, aquele período como de enorme dinamismo, mesmo nas mais difíceis condições, aspecto descrito anos depois:

Tantos artigos de jornal escritos as pressas na banca da redação muitas vezes com o telégrafo ao lado, espiando as laudas de papel uma a uma (...). Tudo vale pouco para os estranhos, porem, relendo aqueles papéis junto a alma tenho as mesmas vibrações que experimentava ao traçar causas, como jornalista do mato (...). Elas todas ainda estão vivas. Ardem todos os dias (PEDROSA, 1934, p. 2).

Assinando os artigos com o pseudônimo de João de Nazareth, que não vem a assumir, inicialmente, passou a fazer suas publicações diárias na Gazeta como profissão de fé e como tarefa profissional. Em artigo intitulado: Meus leitores, o sacerdote apontava as querelas doutrinárias, num devir marcado por arraigada leitura da sociedade de sua época.

Pouco importa a pessoa. Julgen-no atravez dos seus escritos e fiquem todos cer-
tos que não lhe falta fibratura e coragem, para, na hora precisa, apparecer com
todas as letras do seu verdadeiro nome e arrostar de frente erguida a saraivada
das colligações pervesas, o vitupério dos maos, mas sempre de pena em riste,
dizendo verdades, solapando o erro, desafivellando muita mascara que por ahi
afora encobre chagas horrendas e disfarça aleijões moraes de toda especie. Isso na
hora da tormenta, na hora da paz muito manso. Suave acariciando as almas. Com
palavras amigas para tudo e para todos (GAZETA DE NAZARETH, 1929, p. 3).

Entre as fileiras da militância católica, os que como ele se formaram a partir das diretrizes romanizadas, marcavam pontualmente e, se possível diariamente, um programa de reação que se mostrava atento para o debate. Daí a não permitirem discursos que pudessem ser tecidos sem respostas imediatas, sem serem declarantes no que diz respeito a intenções. Todos acabaram com a devida resposta, traduzida na escritura de textos cada vez mais combativos, importando assim para Odilon Pedrosa identificar quem eram os protagonistas seculares em Nazaré da Mata e quais mereciam ser inquiridos e, no tempo certo, "derrotados".

E, da mesma forma, a quem cabia dar combate sem trégua. Aspecto que sinaliza, na homenagem textual que faz aos treze anos da Gazeta de Nazareth, ainda em janeiro de 1929, identificando a proposta de embate: 
Seria para notar-se que essa legião revoltada é a mesma que arroga a si o direito de abocanhar a vida e a honra de outrem, sem restriç̧ão de tempo nem de logar. Não são ainda estas dificuldades que nos farão sustar o passo a arrepiar carreira na caminhada que emprehendemos, militando na imprensa indígena a serviço da boa causa. A postos, os da Gazeta de Nazareth, não fugirão ao labor na salvaguarda dos verdadeiros interesses desta terra (GAZETA DE NAZARETH, 1929, p. 5).

João de Nazareth, ainda no que diz respeito ao edital, que apresentava a nova direção do periódico, apontava diretamente preceitos de endurecimento relacionados às sociabilidades na cidade de Nazaré da Mata, mais particularmente os da instrução não católica ou protestante:

\footnotetext{
Contendores por falsa educação, Contendores por conveniências, Contendores gratuitos e de má fé, Contendores de todos os calibres. Deixando o terreno dos princípios para os factos concretos. Nosso meio social é suficientemente humano para possuir meia duzia de cidadãos, que são refractarios ao progresso desta terra, nos moldes christãos e catholicos. Envenenados de falso liberalismo, sem cultura religiosa adequada, não faltam entre nós amigos que julgam a influencia da Igreja uma pressão de servilismo sobre os homens e as coisas de Nazareth (GAZETA DE NAZARETH, 1929, p. 3).
}

De 1929 a dezembro de 1931 os textos seguiram, num crescendo de ataques e contra-ataques. Na disputa intercalavam-se as vozes da legitimação, para um duplo problema a incomodar sobremaneira Odilon Pedrosa: a expansão do protestantismo em Nazaré da Mata e, no sentido contrário, a afirmação da educação católica. Boa parte dos textos, digase, com escritos que se estenderam por uma larga série de números de a Gazeta.

Ajudava citar e enunciar os avanços do catolicismo mundialmente e na América Latina, bem como, o antagonismo apresentado como símbolo de resistência; na recusa pela instrução não católica de muitos entre os intelectuais e simples devotos; pela ingerência clerical nas sociabilidades cotidianas. A sociedade tem somente que lucrar com o prestigio do clero e sua influencia de bençam e de ordem, diria Odilon Pedrosa sob pseudônimo (GAZETA DE NAZARETH, 1929, p. 3).

O que se apresentava era uma organicidade de fundo político, a se fazer emergir, à medida que Odilon Pedrosa achava seguro questionar os que se lançavam como oposição à Gazeta e à Diocese de Nazaré, a partir da negativização de seus preceitos, inclusive os que incidiam sobre a instrução.

Importava, no trânsito daquela efusão de protagonismos em plena Zona da Mata, que parecessem os inimigos do catolicismo, aos olhos dos leitores de Nazaré da Mata, numa condição de articuladores da desordem, na qualidade de representantes do que Odilon Pedrosa e demais representantes da intelectualidade católica local acreditavam piamente ser uma ameaça: a pouca vontade de obedecer e se submeter à legitimidade católica, inclusive no campo instrucional. Discurso recorrente. 
De qualquer forma, não era sem profunda tenacidade que João de Nazareth destacava os problemas com os quais lidava no bojo de uma cidade, entre o campo e o cosmopolitismo, onde a nos deixarmos levar pelos argumentos tecidos nos textos e polêmicas apresentados nos meses seguintes, a antiga ordem e disciplina estavam por terra a serem corrompidas.

Era, tão-só, imprescindível a arregimentação daquele corpo social e cultural, a partir de uma iniciativa crítica do protestantismo e do liberalismo, ambos colocados como esteio cultural e manifestação societária respectivamente convergentes. Quando administrados na esfera das liberdades irrestritas, traziam, segundo acreditava o diretor da Gazeta, a desestabilização social, assim como as rebeliões armadas.

Como toda escola, possue seus rebelados, os eternos descontentes, não faltará mesmo entre nós um quarto de duzia de bons amigos que procure a todo transe sacudir fora o jugo dos padres (!) que ousam penetrar todos os recantos e cantar nos seus ouvidos a musica incem moda da moralidade, do respeito e da decência social (...) Descem de sua ordem para nivellar-se com os animaes que não pensam, bestializam-se, numa palavra e prorrompem no grito louco da revolta e da liberdade porque é abuso de liberdade, é aberração de liberdade. É fácil ouvir-se nos grupos e reuniões diversas por ahi em fora o zunzum contra a nova ordem de cousas que vai se arraigando na família nazarena (GAZETA DE NAZARETH, 1929, p. 34).

O significado elaborado pelo padre Odilon Pedrosa aos que se rebelavam contra a nova ordem de coisas era justamente o que colocava em lados opostos grupos políticos e ordens sociais não alinhados com a diocese, ou que dela e de seus aliados discordava. Não havia nova ordem, argumentavam os sacerdotes locais, entre eles Odilon Pedrosa, que não fosse a que reconduzia, ou pretendia reconduzir a igreja a um patamar de liderança social, há alguns anos perdido.

Quando Odilon Pedrosa falava da ordem, seria exatamente a de retomada do poder pelas mãos de uma outra oligarquia, ou de grupos simpáticos, imantados a interesses da igreja sensíveis à cultura clerical, com forte tendência a usar a terminologia Revolução, dentro de fronteiras precisas, nunca pelo critério de subversão da ordem, especialmente da ordem intrínseca à sociedade canavieira e ao mandonismo, mas com vistas a tornar executáveis os planos de convergência da igreja em futuros acordos. Mesmo o tenentismo, em ebulição nos anos 1920, ativado pelos processos de embates civis, era visto de forma desconfiada. Sou da Revolução sem Carlos Prestes, diria João de Nazareth, a refletir ainda sobre o que considerava nova ordem.

As estratégias, entretanto, dentro daquela esfera política de Nazaré da Mata, passavam pelo crivo irônico ao abordar adversários, na exposição das práticas jornalísticas que eram identificadas dentro de um prisma depreciativo, não poupando a rispidez ao desfraldar tréplicas, quando da feitura de artigos que considerava inadequados, na maioria das vezes, os que eram escritos por intelectuais não católicos. Em Nazaré da Mata, de foro comumente protestante: 
O jornalismo de aldeia é uma arte bastante difícil porque elle se exerce num circulo fechado de intelligencias rudes, na sua maioria, de homens feitos de susceptibilidade num ambiente de tricas, de murmurações, de preconceitos. Já é um começo de martírio fazer um jornal nessas aldeias do Norte e certamente do sul também. Devemos pisar sobre brasas sem queimar as plantas; adocicar sempre a linguagem para não magoar o vizinho. Sim, a linguagem deve ser de assucar. Muito doce. Os artigos, chronicas e commentários, uma espécie de pílulas de alfenim. Ao contrário viver é um sacrifício. Neste ponto, não nos importa sermos sempre amargos. Preferimos a verdade de fel, a mentira de geléa. É uma questão de princípios. E princípios muito sólidos (GAZETA DE NAZARETH, 1929, p. 23).

É perceptível, a partir de 1929, um ciclo de embates discursivos ainda mais incisivos, direcionados aos intelectuais protestantes e laico-republicanos, na cidade de Nazaré da Mata, cujos editais foram objeto da Gazeta nos meses de junho e outubro daquele ano. É, nesse período, que se dá a materialização das querelas, na manifestação de eventos de grande valor simbólico.

O incidente da depredação de uma imagem de Jesus Cristo, ocorrida em plena praça pública de Nazaré da Mata, foi um marco na verdadeira declaração de guerra discursiva, entre os universos religiosos e de sociabilidades. Na fileira da liderança católica e dos esforços pela identificação dos autores da ação, particularmente como sendo protestantes ou maçons residentes na cidade, esteve Odilon Pedrosa.

Os artífices das ações jornalísticas, a partir do incidente atrelado à imagem do Cristo, impetradas pela igreja como forma de arregimentação diocesana, mergulharam Nazaré da Mata numa guerra de textos, produzidos de forma ininterrupta, por anos a fio. A notícia da depredação parece ter sido a pedra de toque, que levou católicos e protestantes em Nazaré da Mata a um embate contundente.

Odilon Pedrosa, no uso de seu largo conhecimento em direito, apela exatamente para os símbolos que codificam o Estado brasileiro e a moral republicana, onde a defesa do direito à liberdade de culto que ele exalta, contraditoriamente, é a mesma a predispor certo endurecimento frente a toda fé contrária ao catolicismo. Esses que andam por aí no erro apóstata (GAZETA DE NAZARETH, 1929, p. 7).

O sacerdote Odilon Pedrosa não titubeia em defender o caráter laico do mesmo regime, que permite por lei outras confissões, desde que as mesmas, segundo alega João de Nazareth, submetam-se à "autoridade" do Estado, aspecto que diz ser à Igreja Católica, principal articuladora, especialmente de uma relação que só ela, tão-só ela e sua ordem moral, seriam capazes de realizar. Nunca uma escola protestante, por exemplo, teria tal prerrogativa na instrução da juventude. Diria na Gazeta: Ora, o que há de ser feito? Posto que esses antros que ai estão não possuem legitimidade. Quem são esses que se dizem educadores? Que escolas são essas? Traidores de Wintenberg! (GAZETA DE NAZARETH, 1929, p. 3).

Durante anos, até sua saída do meio jornalístico e pedagógico, Odilon Pedrosa defenderia o caráter legítimo do catolicismo como único, capaz de "instruir as vontades" e sedimentar toda e qualquer prática de ética e moral, não cabendo a outra confissão ins- 
truir, de forma ainda mais efetiva a partir de uma representação da ordem civil e de seu disciplinamento.

Notadamente, se não acusa diretamente os protestantes e demais confissões da autoria do crime de vandalismo contra o patrimônio, faz questão de qualificar o evento, dentro de uma das características comportamentais, que vinha identificando serem usuais em Nazaré da Mata: o desrespeito à autoridade clerical, do povo sem instrução do verdadeiro Deus, como diria em edital inflamado (GAZETA DE NAZARETH, 1930, p. 8). Prática que só poderia vir, segundo Odilon Pedrosa, nas entrelinhas, tanto das representações da Igreja Católica que faziam protestantes, maçons e espíritas, quanto da forma como instruíam suas crianças. O Deus que professam nas escolas, se poderíamos chamar escolas, era outro. As seitas de Wintenberg defendiam uma moral ultrajante e instruíam na arte de rebelar-se. A quem cabia rebelar-se? (GAZETA DE NAZARETH, 1930, p. 3).

O padre Odilon Pedrosa, segundo Nascimento (1983), também usaria o pseudônimo Albino Silveira, para publicar uma coluna de crônicas, resenhas e críticas que era denominada: $A$ voz do sabbado. Nesse espaço, usou erudição para atacar diretamente os grupos liberais, quaisquer que fossem, desde republicanos, maçons e intelectuais protestantes.

Na coluna $A$ voz do sabbado, ele realizou um longo exercício de antagonismo projetado na direção do periódico $A$ Voz de Nazareth. Periódico de lastro protestante, adversário direto da Gazeta e forte concorrente na conquista de leitores em Nazaré da Mata, assim como, é importante frisar, nos distritos circunvizinhos.

Era impactante que $A$ voz do sabbado acabasse como uma coluna militante ao representar, diretamente, todo o projeto de cristianização em curso a partir da diocese. Não faltaram oportunidades para o embate:

\footnotetext{
Os talentosos e impavidos jornalistas da voz de Nazareth vieram com uma nova saraivada de insultos que fez estremecer céos e terra. Renovou-se a scena graciosa e veraz daquelles animaizinhos que batidos de azorrague sacodem palas desordenadamente e fogem do cerco em desabrida. Se vergastamos, fazemo-lo com uma crítica seria e ironia complacente, armas admittidas em refregas deste genero. Demais expôem a pelle, porque bem querem, aos açoites impiedosos de nossa analyse. Critiquem-nos tambem, se encontram brecha. Em suas mãos estão as mesmas armas que nós outros brandimos, na defesa da verdade e de nossas convicções (...) (GAZETA DE NAZARETH, 1929, p. 7).
}

Levando em consideração serem os partícipes do periódico $A$ Voz de Nazareth, intelectuais comprometidos com a secularização de costumes, da cultura e parte considerável deles articulistas protestantes, as provocações - de ambas as partes - só avançaram. É afinal, junto a esses dragões da tradição podre da Sé, onde se alimentam as escolas públicas e privadas de nossa cidade? Tenhamos pena de nossas crianças sob o chicote de Roma (A VOZ DE NAZARETH, 1930, p. 1). A Voz de Sabbado responderia aos textos produzidos e ideias publicizadas, naquele periódico liberal, como postulados elaborados para tomar o território da cristandade católica desestabilizado. Deviam ser eliminados, purgados, destratados na mesma medida (PEDROSA, 1930, p. 4). 
A Voz de Nazareth reagia quase que diariamente: É Lutero o grande mestre da instrução. Que moral possui um Papa? (A VOZ DE NAZARETH, 1930, p. 4). Na mesma moeda respondia A Voz do Sabbado: Eis os imorais a tentarem as escolas com as mentiras teutônicas. Qual família deve confiar seus filhos a um pastor? Tem ele qualquer formação moral, espiritual ou pedagógica para tanto? Temos nossas dúvidas (GAZETA DE NAZARETH, 1930, p. 4).

O comentário à Carta Pastoral de Dom Vilela junto aos fiéis católicos de Nazaré da Mata, em 1929, publicada na Gazeta, foi um exemplo entre muitos de uma ação de militância encaminhada por Odilon Alves, em que se cristalizava todo repúdio à secularização, à medida que se intensificavam a implantação de colégios protestantes em Pernambuco (SELARO, 2009, p. 34) e demais reformas na instrução pública/particular a ocorrerem por todo o Brasil.

\section{CONSIDERaÇões FINAIS}

Nos anos de 1930, foram potencializadas batalhas discursivas entre as mentalidades liberal/confessional de forma a se perpetrarem antagonismos duradouros. Alguns deles, postulados para a instrução, precipitaram uma segunda leva de acirramentos discursivos numa profusão de textos de engajamento. Ensino livre, universal, laico e público, enquanto demandas educacionais naqueles tempos tornaram ainda mais difícil a relação entre os interesses de expansão da igreja a partir do ensino religioso e o corpo geral de princípios liberais propostos pelos tenentes vencedores de 1930, bem como, seus pares.

Daí, também, a reação de intelectuais católicos romanizados à liberdade e presença de modelos instrucionais, como o protestante, na sociedade brasileira. Aquela mesma a se apresentar em trânsito, dado o vertiginoso processo de mudança que se apresentava, segundo Neves (1994, p. 34), e na qual importava para a igreja se adiantar, sob pena de perda de espaço, notadamente nos ambientes intelectuais jornalísticos nos quais Odilon Pedrosa era protagonista, mas também franco adversário quando os mesmos eram arquitetados por uma conhecida ordem societária autônoma, aquela que foi crítica voraz da Igreja Católica no âmbito escolar/instrucional.

Alguns ideais, lembremos, sintetizados na declaração de princípios francamente disposta entre os intelectuais denominados escolanovistas. Alguns deles, como Anísio Teixeira e Fernando Azevedo, dois dos organizadores do Manifesto de 1932, acompanhados de perto pelo intelectual-sacerdote pernambucano, especialmente no que dizia respeito ao constructo de propostas reformadoras, que eram publicizadas a partir de livros ou artigos. Aquelas propostas, diga-se, a potencializarem uma marcante dicotomia entre a geração de padres formados em Roma nos anos de 1920 e intelectuais secularistas, no período imediatamente posterior ao movimento de 1930, a ocuparem cargos de liderança no magistério, e meios de publicização doutrinária, como os que se apresentavam na Gazeta de Nazareth, sob a direção de Odilon Alves Pedrosa. 


\section{REFERÊNCIAS}

ALMANAK ADMINSTRATIVO, Mercantil e industrial do Rio de Janeiro. Rio de Janeiro, 1931.

AZZI, Riolando. História da Igreja no Brasil: Terceira Época: 1930-1964. Rio de Janeiro: Vozes, 2008, p. 34-50.

BOURDIEU, Pierre. O Poder Simbólico. Rio de Janeiro: Bertrand Brasil, 2007.

CAMBI, Franco. História da Pedagogia. São Paulo: EDUSP, 2002.

CATROGA, Fernando. Entre Deuses e Cesares. Lisboa: Almeidina, 2010.

KULESZA, Andrej Wojciech. A Igreja na Primeira República. In: MACHADO, Charliton José dos Santos; SCOCUGLIA, Afonso Celso (Org.). Pesquisa e historiografia da educação brasileira. São Paulo: Editora Autores Associados, 2006.

. Os Seminários como locais de formação Docente. In: CARDOSO, Carlos de Amorim; KULESZA, Andrej Wojciech (Org.). A Escola e a Igreja nas Ruas da Cidade. João Pessoa: Editora Universitária da UFPB, 2010.

MARRAMAO, Giacomo. Poder e Secularização. As categorias do Tempo. São Paulo: UNESP, 1994.

MICELI, Sérgio. A Elite Eclesiástica brasileira, 1890-1930. Rio de Janeiro: Bertrand, 1988. NASCIMENTO, Luiz do. História da imprensa em Pernambuco. Recife: Universidade Federal de Pernambuco, 1997, v. XIII.

PEDROSA, Odilon Alves. Caminhos Andados. João Pessoa: Unigraf, 1986.

. Diário do Seminário. Manuscrito. Olinda, 1927.

. Do meu Bisaco. João Pessoa: Editora Unigraf, 1988.

. Recortes dos artigos que publiquei na Gazeta de Nazareth, 1931-1935. Nazaré da Mata: Impresso, 1935.

PESSOA, Marliete de Lira. Os 80 anos do Colégio Santa Cristina: uma história de educação e fé. Nazaré da Mata, PE: Ed. do Autor, 2003.

SELLARO, LÊDA Rejane Accioly. Educacão e modernidade em Pernambuco: inovações no ensino público (1920-1937). Recife: Editora Universitária, UFPE, 2009.

SILVA, Ramsés Nunes e. Signal dos Tempos: modernidade, secularização e laicização na instrução pública da Parahyba do Norte (1867-1902), 2006. Dissertação (Mestrado) PPGE, Universidade Federal da Paraíba, 2006.

SKIDMORE, Thomas E. Brasil: De Getulio Vargas a Castelo Branco, 7. ed. Rio de Janeiro: Paz e Terra, 1982. 
VILLAÇA, Antônio Carlos. O Pensamento Católico no Brasil. Rio de Janeiro: Civilização Brasileira, 2006.

\section{IMPRESSOS}

GAZETA DE NAZARETH. Algumas verdades, v. 1, n. 5, Nazaré da Mata, 1929.

. Algumas verdades, v. 3, n. 4, Nazaré da Mata, 1929.

. O Catholicismo no Japão, v. 3, n. 4, Nazaré da Mata, 1929.

. Algumas verdades, v. 1, n. 7, Nazaré da Mata, 1930.

. Sou da Revolução, v. 3, n. 6, Nazaré da Mata, 1930.

. A História de um artigo, v. 3, n. 7, Nazaré da Mata, 1930.

. O perigo da escola teotônica, v. 4, n. 7, Nazaré da Mata, 1930.

Ramsés Nunes e Silva é Historiador, com mestrado e doutorado em Educação pela Universidade Federal da Paraíba. É professor do departamento de Arquivologia UEPB (Universidade Estadual da Paraíba). Investiga Arquivos escolares, representações sobre o ensino confessional e querelas discursivas entre o universo instrucional religioso e a secularização educacional.

Submetido em: 12/05/2017

Aprovado em: 18/06/2018 